\title{
Political tension and stock markets in the Arabian Peninsula
}

\author{
Alanoud Al-Maadid ${ }^{1}$ | Guglielmo Maria Caporale ${ }^{2}$ (D) Fabio Spagnolo $^{2}$ | \\ Nicola Spagnolo ${ }^{2,3}$
}

${ }^{1}$ College of Economics and Finance, Qatar University, Doha, Qatar

${ }^{2}$ Department of Economics and Finance, Brunel University London, London, UK

${ }^{3}$ Centre for Applied Macroeconomic Analysis (CAMA), Australian National University, Canberra, Australian Capital Territory, Australia

\section{Correspondence}

Guglielmo Maria Caporale, Department of Economics and Finance, Brunel University London, London, UK. Email:

Guglielmo-Maria.Caporale@brunel.ac.uk

\begin{abstract}
This note investigates the effects of the recent political tensions in the Arabian peninsula on the linkages between the stock markets of the leading Gulf Cooperation Council countries by estimating a VAR-GARCH( $(1,1)$ model at a weekly frequency. The results indicate that the June 2017 crisis lowered stock market returns and generally led to greater volatility spillovers within the region. This evidence supports the need for further financial integration and suggests fewer portfolio diversification opportunities for investors in the Gulf Cooperation Council region.
\end{abstract}

\section{KEYWORDS}

GCC, multivariate GARCH, political tension

JEL CLASSIFICATION

C32; F36; G15;

\section{1 | INTRODUCTION}

It is often argued that political instability can disrupt financial markets by increasing uncertainty. In his famous book, Knight (1921) distinguished between risk and uncertainty to describe situations whose outcomes are unknown but governed by a known or an unknown probability model, respectively. However, the literature on the linkages between political developments and stock markets tends to use the two terms almost interchangeably. Specifically, political risk is usually defined as the risk an investment's returns could suffer as a result of political changes or instability in a country (this is also known as "geopolitical risk"). Similarly, political uncertainty often refers to economic risk resulting from uncertainty about the future path of monetary or fiscal policy, which might raise risk premia and induce agents to delay spending and investment.

For instance, Boutchkova et al. (2012) examined the effects of local and global political risk on the volatility of industry returns using panel data for fifty countries from
1990 to 2006 , their political risk index being based on measures of government stability, socioeconomic conditions, investment risk, risk of internal conflict, external conflict, corruption, the involvement of the military in politics, religious tensions, ethnic tensions, democratic accountability, and quality of bureaucracy; they found that industries that are more dependent on trade, contract enforcement, and labour exhibit greater return volatility when political uncertainty increases either locally or in their trading partners; moreover, whereas systematic volatility is associated with domestic political uncertainty, global political risks translate into larger idiosyncratic volatility. Hartwell (2017) investigated the impact of formal (i.e., elections) and informal (i.e., internal/external conflicts; Fernandez, 2007) political volatility; he reported that the latter has a significant negative effect on the level of stock returns, whereas the former mainly affects stock returns volatility.

The literature concerning specifically the Gulf Cooperation Council (GCC) countries (namely Bahrain, Qatar, Kuwait, Oman, UAE, and Saudi Arabia) is 
extremely limited. Chaua et al. (2014) found that political uncertainty, following the 2011 "Arab Spring," had a greater impact on the volatility of Islamic rather than conventional stock markets indices in the Middle East and North African region, which includes the GCC countries (namely, Bahrain, Qatar, Kuwait, Oman, UAE, and Saudi Arabia). Sedik and Willliams (2011) showed that GCC equity markets are exposed to global as well as regional shocks; the presence of sizeable cross-border spillovers within the region points to the need for coordination.

This note focuses on the effects of the recent political tensions in the Arabian peninsula on the stock markets of the GCC countries. The GCC was established in 1981 and has recently launched a series of economic projects aimed at promoting financial integration as well as improving compliance with international standards. Its members, currently engaged in the transformation of their economies through a process of opening up and industry diversification, have benefited from being oil and gas producers. This has had a positive effect on stock market capitalisation in the region. ${ }^{1}$ On 5 March 2014, Bahrain, Saudi Arabia, and the UAE pulled their diplomats out of Qatar claiming that this state was providing financial and logistical support to international terrorism and was therefore threatening the stability of the Gulf States. More recently, on 5 June 2017, their diplomatic relations with Qatar soured again, which led to the suspension of transport ties and the request that Qatari visitors and residents should leave within 2 weeks. Egypt then imposed a land, sea, and air blockade on Qatar. The six GCC countries do little merchandise trade with each other, instead relying on imports from outside the region, and therefore Qatar's liquefied natural gas shipments by sea were expected to continue normally. However, the Qatar Stock Exchange dropped by $6.38 \%$ (Reuter).

This note investigates whether the 2017 political crisis affected the dynamic linkages between the GCC stock markets and their degree of financial integration. It makes a threefold contribution. First, it focuses on a group of emerging markets (UAE, Qatar, and Saudi Arabia), for which very little information is available. Second, in contrast to most existing papers in this area of the literature, it models the dynamic interactions between both the first and the second moments of the variables of interest. Third, it controls for the 2017 financial crisis and other important exogenous variables. The layout is as follows. Section 2 outlines the econometric modelling approach. Section 3 presents the empirical results. Section 4 summarizes the main findings and offers some concluding remarks.

\section{2 | THE MODEL}

We model the joint process governing stock market returns indices in the three GCC largest markets using a trivariate
VAR-GARCH(1,1) framework. ${ }^{2}$ In its most general specification the model takes the following form as follows:

$$
x_{t}=\alpha+\beta x_{t-1}+\delta f_{t-1}+u_{t},
$$

where $x_{t}=\left(\mathrm{UAE}_{t}\right.$, Qatar $_{t}$, Saudi Arabia $\left.{ }_{t}\right)$ and $\mathbf{x}_{t-1}$ is the corresponding vector of lagged variables. We include in the mean equation a vector of control variables given by $\mathbf{f}_{t}=\left(\right.$ Int. Rate $_{t}, \mathrm{VIX}_{t}, \mathrm{Oil}_{t}$ ), namely the domestic 3-month Treasury Bill rate and the VIX, as proxies for monetary policy and global financial shocks, as well as Brent crude oil prices. In order to account for the possible effects of the recent political tension, we also include one dummy variable with a switch in June 2017 (denoted by ${ }^{*}$ ), that is, on the days of the political tension with a land, sea, and air blockade imposed on Qatar by the UAE and Saudi Arabia. The residual vector $\mathbf{u}_{t}=\left(u_{1, t}, u_{2, t}, u_{3, t}\right)$ is trivariate and normally distributed $\mathbf{u}_{t} \mid I_{t-1} \sim\left(\mathbf{0}, H_{t}\right)$, its conditional variance covariance matrix being given by

$$
H_{t}=\left[\begin{array}{lll}
h_{11 t} & h_{12 t} & h_{13 t} \\
h_{12 t} & h_{22 t} & h_{23 t} \\
h_{13 t} & h_{23 t} & h_{33 t}
\end{array}\right] .
$$

The parameter vector of the mean return Equation (1) includes $\alpha=\left(\alpha_{1}+\alpha_{1}^{*}, \alpha_{2}+\alpha_{2}^{*}, \alpha_{3}+\alpha_{3}^{*}\right)$, which are the constants, and the autoregressive term, which measures the mean spillover effects. The parameter $\beta$ is defined as $\beta=\left(\beta_{11}, \beta_{12}+\beta_{12}^{*}, \beta_{13}+\beta_{13}^{*}\left|\beta_{21}+\beta_{21}^{*}, \beta_{22}, \beta_{23}+\beta_{23}^{*}\right| \beta_{31}+\right.$ $\beta_{31}^{*}, \beta_{23}+\beta_{32}^{*}, \beta_{33}$ ). Furthermore, $\delta=$ (Int.UAE, VIX, Oil|Int.Qatar, VIX, Oil|Int.saudi, VIX, Oil) is the vector of control parameters for monetary policy, global exogenous shocks, and crude oil, respectively. ${ }^{3}$ The second moment takes the following form:

$$
H_{t}=C^{\prime} C+A^{\prime}\left[\begin{array}{ccc}
e_{1, t-1}^{2} & e_{2, t-1} e_{1, t-1} & e_{3, t-1} e_{1, t-1} \\
e_{1, t-1} e_{2, t-1} & e_{2, t-1}^{2} & e_{3, t-1} e_{2, t-1} \\
e_{1, t-1} e_{3, t-1} & e_{2, t-1} e_{3, t-1} & e_{3, t-1}^{2}
\end{array}\right] A+G^{\prime} H_{t-1} G,
$$

where

$$
\begin{aligned}
& A=\left[\begin{array}{lll}
a_{11} & a_{12}+a_{12}^{*} & a_{13}+a_{13}^{*} \\
a_{21}+a_{21}^{*} & a_{22} & a_{23}+a_{23}^{*} \\
a_{31}+a_{31}^{*} & a_{32}+a_{32}^{*} & a_{33}
\end{array}\right] ; \\
& G=\left[\begin{array}{lll}
g_{11} & g_{12}+g_{12}^{*} & g_{13}+g_{13}^{*} \\
g_{21}+g_{21}^{*} & g_{22} & g_{23}+g_{23}^{*} \\
g_{31}+g_{31}^{*} & g_{32}+g_{32}^{*} & g_{33}
\end{array}\right],
\end{aligned}
$$

Equation (3) models the dynamic process of $H_{t}$ as a linear function of its own past values $H_{t-1}$ and past values of the squared innovations $\left(e_{1, t-1}^{2}, e_{2, t-1}^{2}, e_{3, t-1}^{2}\right)$. The parameters of (3) are given by $C$ (which is restricted to be upper triangular) and the two matrices $A$ and $G$.This allows us to test, for instance, for volatility spillovers 
(causality-in-variance) from UAE stock return volatility to Qatar stock return volatility before $\left(a_{21}\right)$ and after the political crisis $\left(a_{21}+a_{21}^{*}\right)$. The Baba, Engle, Kraft, and Kroner representation guarantees by construction that the covariance matrix in the system is positive definite. Furthermore, the conditional correlations between the three markets are given by $\boldsymbol{\rho}_{12, t}=h_{12, t} / \sqrt{h_{11, t}} \sqrt{h_{22, t}}$, $\boldsymbol{\rho}_{13, t}=h_{13, t} / \sqrt{h_{11, t}} \sqrt{h_{33, t}}$ and $\boldsymbol{\rho}_{23, t}=h_{23, t} / \sqrt{h_{22, t}} \sqrt{h_{33, t}}$. The standard errors, and associated $p$ values, are calculated using the quasi-maximum likelihood methods of Bollerslev and Wooldridge (1992), which is robust to the distribution of the underlying residuals.

\section{3 | EMPIRICAL ANALYSIS}

We use weekly data (from Bloomberg) on stock returns of a selected group of GCC markets (UAE, Qatar, and Saudi Arabia) over the period October 2010 to May 2018, for a total of 400 observations, weekly returns being defined as the logarithmic differences of stock market indexes. The data for the Brent crude oil prices, domestic interest rates, and VIX are also collected from Bloomberg. The weekly frequency is chosen to overcome the problem of asynchronous trading (with the United States) that is present in the case of daily data and would bias some of the results. In order to test the adequacy of the models, Ljung- Box portmanteau tests were performed on the standardized and squared standardized residuals. Overall, the results indicate that the specification adopted is data congruent and captures satisfactorily the persistence of stock returns and their volatility.

The presence of mean and volatility spillovers is then tested by means of Wald tests for the relevant parameter restrictions. For instance, when considering the UAE and Qatar pair, the following null hypotheses are tested: (a) mean spillover effects before the 2017 surge in political tension $\left(\beta_{12}=0 ; \beta_{21}=0\right)$; (b) mean spillover effects after the 2017 surge in political tension $\left(\beta_{12}^{*}=\right.$ $\left.0 ; \beta_{21}^{*}=0\right)$; (c) volatility spillovers before the 2017 events $\left(a_{21}=g_{21}=0 ; a_{12}=g_{12}=0\right)$; (d) volatility spillovers after the 2017 events $\left(a_{21}^{*}=g_{21}^{*}=0 ; a_{12}^{*}=g_{12}^{*}=0\right)$; and finally, (e) a shift in the conditional means of stock returns after the 2017 events $\left(\alpha_{11}^{*}=0 ; \alpha_{22}^{*}=0\right) .^{5}$

Summary statistics are displayed in Panel A of Tables 1. The mean weekly change for stock returns is positive for all countries, with the UAE stock market showing the highest returns (0.026), followed by the Saudi Arabia (0.005), and Qatar (0.001) ones. The standard deviations show a similar pattern, with the highest volatility occurring in the case of the UAE (1.902), followed by Saudi Arabia (1.049), and Qatar (0.978).
Cross-market dependence in the conditional mean and variance vary in magnitude and sign across countries. ${ }^{6}$ The estimated VAR-GARCH $(1,1)$ model with associated robust $p$ values and likelihoods are reported in Panel B of Table 1. We select the optimal lag length of the mean equation using the Schwarz information criterion. It is noteworthy that the conditional means were strongly and negatively influenced by the political crisis in the cases of Qatar $\left(\alpha_{2}^{*}=-0.035\right)$ and the UAE $\left(\alpha_{1}^{*}=-0.101\right)$, with average losses of $30 \%$ and $50 \%$, respectively, whereas there was no effect in Saudi Arabia. The parameter estimates for the conditional means suggest positive and statistically significant spillovers-in-mean at the standard 5\% significance level across all markets with the exception of those running from Saudi Arabia to the UAE. Spillovers originating from Qatar influence negatively the UAE and Saudi Arabia stock market returns. The size of the spillover effects running from the UAE to Saudi Arabia and Qatar increased and decreased, respectively, after the 2017 political crisis. The largest increase is observed in the case of spillovers running from Saudi Arabia to Qatar $\left(\beta_{23}^{*}=0.452\right)$. All other cross market spillovers do not appear to have been influenced by the 2017 political crisis.

Concerning the conditional variance equations, the estimated "own-market" coefficients are statistically significant and the estimates of $g_{11}, g_{22}$, and $g_{33}$ suggest a high degree of persistence. The results reported in Panel B of Table 1 can be summarized as follows. First, there are significant volatility spillovers originating from the UAE, the corresponding coefficient (in absolute value) being largest in the case of volatility spillovers from UAE to Qatar $\left(a_{21}=-0.427\right)$; further, its size increased after the 2017 crisis $\left(a_{21}+a_{21}^{*}=-0.752\right)$. The largest increase in volatility spillovers after the crisis occurred in the case of those from Qatar to the UAE $\left(a_{12}+a_{12}^{*}=1.831\right)$ compared with the pre-June 2017 period $\left(a_{12}=0.255\right)$. Spillovers running from Saudi Arabia to the UAE are only significant before the crisis $\left(a_{13}=0.201\right)$, whereas those towards Qatar are large after the crisis $\left(a_{23}^{*}=-0.558\right)$.

Further, the exogenous control variables are statistically significant for all three countries. The estimated coefficients indicate a negative effect of global risk (measured by the VIX) and monetary policy (measured by the domestic interest rate) and a positive one of oil prices. $^{7}$

Finally, the conditional correlations obtained from the VAR-GARCH $(1,1)$ model (see Table 1, Panel A) also provide evidence of comovement across stock market returns; in particular, they are all positive before and after June 2017. However, there is a noticeable downward shift in the case of the mean correlation between the UAE and Qatar 
TABLE 1 Descriptive statistics and estimated model results

\begin{tabular}{|c|c|c|c|c|c|c|c|c|c|}
\hline \multicolumn{10}{|c|}{ Panel A: Descriptive statistics and conditional correlations } \\
\hline & UAE & Qatar & Saudi Arabia & & & Pre 2017 & UAE & Qatar & Saudi Arabia \\
\hline Mean & 0.026 & 0.001 & 0.005 & & & UAE & 1 & 0.121 & 0.418 \\
\hline St. Dev. & 1.902 & 0.978 & 1.049 & & & Qatar & & 1 & $\begin{array}{c}0.377 \\
0.043\end{array}$ \\
\hline Min & -2.993 & -1.261 & -1.431 & & & Saudi A. & & & 1 \\
\hline Max & 0.433 & 0.268 & 0.304 & & & & & & \\
\hline Skewnes & -0.701 & -0.462 & -1.057 & & & Post 2017 & UAE & Qatar & Saudi Arabia \\
\hline Kurtosis & 9.891 & 5.887 & 7.601 & & & UAE & 1 & 0.045 & 0.555 \\
\hline & & & & & & $\begin{array}{l}\text { Qatar } \\
\text { Saudi A. }\end{array}$ & & 1 & $\begin{array}{l}0.379 \\
0.201 \\
1\end{array}$ \\
\hline Panel B: & $\begin{array}{r}\text { Estimat } \\
\text { Coeffic } \\
\text { Conditi }\end{array}$ & $\begin{array}{r}\mathrm{R}-\mathrm{GARC} \\
p \text { value } \\
\text { nean equ }\end{array}$ & $\begin{array}{l}\mathrm{H}(1,1) \text { model } \\
\text { tion }\end{array}$ & Coefficient & $p$ value & & & Coefficient & $p$ value \\
\hline$\alpha_{1}$ & 0.216 & $(.000)$ & $\beta_{12}$ & -0.179 & $(.004)$ & & $\beta_{12}^{*}$ & 0.104 & $(.099)$ \\
\hline$\alpha_{2}$ & 0.099 & $(.019)$ & $\beta_{13}$ & 0.044 & $(.381)$ & & $\beta_{13}^{*}$ & -0.058 & $(.343)$ \\
\hline$\alpha_{3}$ & 0.096 & $(.000)$ & $\beta_{21}$ & 0.057 & $(.009)$ & & $\beta_{21}^{*}$ & -0.101 & $(.000)$ \\
\hline$\alpha_{1}^{*}$ & -0.101 & $(.000)$ & $\beta_{23}$ & 0.065 & $(.081)$ & & $\beta_{23}^{*}$ & 0.452 & $(.000)$ \\
\hline$\alpha_{2}^{*}$ & -0.035 & $(.037)$ & $\beta_{31}$ & 0.069 & $(.012)$ & & $\beta_{31}^{*}$ & 0.121 & $(.000)$ \\
\hline$\alpha_{3}^{*}$ & -0.022 & $(.146)$ & $\beta_{32}$ & -0.106 & $(.041)$ & & $\beta_{32}^{*}$ & 0.027 & $(.618)$ \\
\hline$\beta_{11}$ & 0.315 & $(.000)$ & $\beta_{22}$ & 0.116 & $(.000)$ & & $\beta_{33}$ & 0.261 & $(.000)$ \\
\hline Oil $\mathrm{U}_{t-1}$ & 0.025 & $(.000)$ & Oil $Q_{t-1}$ & 0.021 & $(.000)$ & & Oil $S_{t-1}$ & 0.023 & $(.000)$ \\
\hline VIX $U_{t-1}$ & -0.052 & $(.001)$ & VIX $Q_{t-1}$ & -0.034 & $(.045)$ & & VIX S $S_{t-1}$ & -0.051 & $(.000)$ \\
\hline Int. $\mathrm{U}_{t-1}$ & -0.062 & $(.000)$ & Int. $\mathrm{Q}_{t-1}$ & -0.017 & $(.008)$ & & Int. $\mathrm{S}_{t-1}$ & -0.001 & $(.582)$ \\
\hline \multicolumn{10}{|c|}{ Conditional variance equation } \\
\hline$c_{11}$ & 0.154 & $(.000)$ & $a_{12}$ & 0.255 & $(.000)$ & & $g_{12}$ & -0.019 & $(.601)$ \\
\hline$c_{22}$ & 0.127 & $(.000)$ & $a_{21}$ & -0.427 & $(.000)$ & & $g_{21}$ & 0.786 & $(.000)$ \\
\hline$c_{33}$ & 0.009 & $(.051)$ & $a_{13}$ & 0.201 & $(.000)$ & & $g_{13}$ & 0.137 & $(.000)$ \\
\hline$c_{11}^{*}$ & -0.027 & $(.000)$ & $a_{31}$ & -0.235 & $(.029)$ & & $g_{31}$ & 0.315 & $(.000)$ \\
\hline$c_{22}^{*}$ & 0.196 & $(.000)$ & $a_{23}$ & -0.063 & $(.411)$ & & $g_{23}$ & -0.417 & $(.000)$ \\
\hline$c_{33}^{*}$ & 0.006 & $(.049)$ & $a_{32}$ & -0.128 & $(.014)$ & & $g_{32}$ & 0.267 & $(.000)$ \\
\hline$a_{11}$ & 0.219 & $(.000)$ & $a_{12}^{*}$ & 1.576 & $(.000)$ & & $g_{12}^{*}$ & -0.724 & $(.000)$ \\
\hline$a_{22}$ & 0.114 & $(.000)$ & $a_{21}^{*}$ & -0.325 & $(.000)$ & & $g_{21}^{*}$ & -0.901 & $(.000)$ \\
\hline$a_{33}$ & 0.317 & $(.000)$ & $a_{13}^{*}$ & 0.017 & $(.522)$ & & $g_{13}^{*}$ & -0.797 & $(.000)$ \\
\hline$g_{11}$ & 0.719 & $(.000)$ & $a_{31}^{*}$ & 0.285 & $(.002)$ & & $g_{31}^{*}$ & 0.192 & $(.000)$ \\
\hline$g_{22}$ & 0.797 & $(.000)$ & $a_{23}^{3}$ & -0.558 & $(.000)$ & & $g_{23}^{*}$ & 0.406 & $(.000)$ \\
\hline$g_{33}$ & 0.895 & $(.000)$ & $a_{32}^{*}$ & -0.543 & $(.000)$ & & $g_{32}^{*}$ & 1.021 & $(.000)$ \\
\hline $\mathrm{LB}_{(4)} \mathrm{Q}$ & 3.429 & $(.488)$ & $\mathrm{LB}_{(4)} \mathrm{S}$ & 5.066 & $(.281)$ & & $\mathrm{LB}_{(4)} \mathrm{U}$ & 3.374 & $(.497)$ \\
\hline $\left.\mathrm{LB}_{(4)}^{2}\right) \mathrm{Q}$ & 5.189 & $(.266)$ & $\left.\mathrm{LB}_{(4)}^{2}\right) \mathrm{S}$ & 3.211 & $(.201)$ & & $\left.\mathrm{LB}_{(4)}^{2}\right) \mathrm{U}$ & 2.166 & $(.705)$ \\
\hline Log-lik & 229.67 & & & & & & & & \\
\hline
\end{tabular}

Note. Stock market returns are the percentage changes in stock indexes. The sample size covers the period June 2010 to May 2018 , for a total of 399 observations. $p$ values are calculated using the quasi-maximum likelihood method of Bollerslev and Wooldridge (1992), which is robust to the distribution of the underlying residuals, and reported in brackets. $\mathrm{LB}_{(4)}$ and $\mathrm{LB}_{(4)}^{2}$ are the Ljung and Box (1978) of significance of autocorrelations of four lags in the standardized and standardized squared residuals, respectively. The parameters $\beta_{12}$ and $\beta_{13}$ measure the Granger causality effect of Qatar and Saudi Arabia on UAE stock market returns, respectively. $a_{12}$ and $a_{13}$ measure the Granger causality effect of Qatari and Saudi Arabia market returns volatility on the UAE stock market returns volatility, respectively. The effect of political tensions (June 2017) is measured by $\left(\beta_{12}+\beta_{12}^{*}\right)$ and $\left(\beta_{13}+\beta_{13}^{*}\right)$, in mean, and by $\left(a_{12}+a_{12}^{*}\right)$ and $\left(a_{13}+a_{13}^{*}\right)$, in variance. The covariance stationarity condition is satisfied by all the estimated models, all the eigenvalues of $A \otimes A+G \otimes G$ being less than one in modulus. Conditional correlations between stock market returns are given by $\rho_{12, t}=h_{12, t} / \sqrt{h_{11, t}} \sqrt{h_{22, t}}, \rho_{13, t}=h_{13, t} / \sqrt{h_{11, t}} \sqrt{h_{33, t}}$ and $\rho_{23, t}=h_{23, t} / \sqrt{h_{22, t}} \sqrt{h_{33, t}}$. Averages of pre and post 2017 conditional correlations are reported in Panel A.

in the second period (from 0.121 to 0.045 ) and an upward shift in the case of the UAE-Saudi Arabia one (from 0.418 to 0.555). As for those between Qatar and Saudi Arabia, although the mean correlation is essentially the same, the variance one increases in the second subsample. In brief, the June 2017 political crisis seems to have affected correlations involving the UAE, but not those between Saudi Arabia and Qatar. 


\section{4 | CONCLUSIONS}

This note uses a VAR-GARCH $(1,1)$ model to analyse the possible effects of the June 2017 financial crisis in the Arabian peninsula on the linkages between the stock markets of the leading GCC countries. Our results suggest that volatility spillovers within the region have generally become stronger as a result of the recent political tensions and have therefore made individual markets more vulnerable to turbulence originating from other markets in the region. In terms of policy implications, this evidence strengthens the argument for further financial integration (possibly including the introduction of a single currency) in order to deal with a possible decline in risk appetite following the crisis, regardless of the degree of integration of this region with the developed economies (Wang et al., 2017), and to attenuate the impact of external common shocks, as the Asian experience has previously shown (Asian Development Bank, 2013). Further, it implies that fewer portfolio diversification opportunities are available in the region for hedge funds and institutional investors.

\section{ACKNOWLEDGEMENTS}

We would like to thank the editor and two anonimous referees for very helpful comments and suggestions. The first author would also like to thank Qatar University for financial support, Grant QUCP-CBE-2018-1. The findings are solely the responsibility of the authors.

\section{ENDNOTES}

1 In 2017, this was USD451bn in Saudi Arabia, USD132bn in Abu Dhabi, USD130bn in Qatar, USD104bn in Dubai, and slightly lower in Bahrain, Kuwait, and Oman. Our analysis therefore focuses on the first three countries because they have the biggest stock markets and can be seen as representative of the region as a whole.

2 The model is based on the Baba, Engle, Kraft, and Kroner representation proposed by Engle and Kroner (1995). This specification was preferred to a set of competing models, such as the DCC-GARCH family, given the relatively small number of markets considered and the rather high number of parameters to be estimated.

3 These variables are treated as exogenous in order to obtain a system of equations of manageable dimensions; both are lagged in order to control for any potential endogeneity and to capture the often non-contemporaneous effects of monetary and global financial variables. The number of parameters in general has been chosen to make the estimation feasible given the available sample size.

4 We use the Dubai stock market returns as a proxy for the UAE ones. The results obtained using the Abu Dhabi stock market data were qualitatively similar and are not reported for space constrain, but are available upon request.

5 Appropriate empirical critical values are computed by means of bootstrapping.

6 Note that the sign in cross-market volatilities are not relevant.

7 Trade could also be a significant factor driving the stock returns of these emerging markets because all three countries are net exporters of natural resources and net importers of consumable goods. However, this hypothesis cannot be tested directly using our framework, given the low frequency of the data on trade.

\section{ORCID}

Guglielmo Maria Caporale (D) https://orcid.org/

0000-0002-0144-4135

\section{REFERENCES}

Asian Development Bank (2013). "Regional cooperation and integration”, in Asian Development Bank (Ed.Asian Economic Integration Monitor. Asian Development Bank.

Bollerslev, T., \& Wooldridge, J. M. (1992). Quasi-maximum likelihood estimation and inference in dynamic models with time-varying covariances. Econometric Reviews, 11, 143-172.

Boutchkova, M., Doshi, H., Durnev, A., \& Molchanov, A. (2012). Precarious politics and return volatility. The Review of Financial Studies, 25, 1111-1154.

Chaua, F., Deesomsaka, R., \& Durham, J. W. (2014). Political uncertainty and stock market volatility in the Middle East and North African (MENA) countries. Journal of International Financial Markets, Institutions and Money, 28, 1-19.

Engle, R. F., \& Kroner, K. F. (1995). Multivariate simultaneous generalized ARCH. Econometric Theory, 11, 122-150.

Fernandez, V. (2007). Stock market turmoil: Worldwide effects of middle east conflicts. Emerging Markets Finance and Trade, 43(3), 58-102.

Hartwell, C. A. (2017). The effect of political volatility on capital markets in EU accession and neighborhood countries. Journal of Economic Policy Reform, 1-22.

Knight, F. H. (1921). Risk, uncertainty, and profit. Boston. MA: Hart, Schaffner and Marx; Houghton Mifflin Company.

Ljung, G. M., \& Box, G. E. P. (1978). On a measure of lack of fit in time series models. Biometrika, 65, 297-303.

Sedik, T. S., \& Willams, O. (2011). Global and regional spillovers to GCC equity markets. (IMF Working Paper, WP/11/138) International Monetary Fund.

Wang, Q., Zhu, Y., Yang, L., \& Mul, R. A. H. (2017). Coupling detrended fluctuation analysis of asian stock markets. Physica $A$, 471, 337-350.

How to cite this article: Al-Maadid A, Caporale GM, Spagnolo F, Spagnolo N. Political tension and stock markets in the Arabian peninsula. Int J Fin Econ. 2020;1-5. https://doi.org/10.1002/ijfe.1810 